\title{
Türkiye'de Azot Kullanım Etkinliğinin İyileştirilmesinin Tarım Ekonomisine Katkısının Değerlendirilmesi
}

\author{
Fethi Şaban ÖZBEK \\ Türkiye İstatistik Kurumu ${ }^{1}$, Devlet Mah. Necatibey Cad. No:114 06420 Çankaya/ANKARA \\ [ORCID: https://orcid.org/0000-0002-0167-8222] \\ Sorumlu yazar: fethiozbek@gmail.com
}

\begin{abstract}
Öz
Bu çalışma ile 2007-2011 yılları için tarımsal alanlarda azot kullanım etkinliğinin (AKE) belirli oranlarda iyileştirilmesinin tarım ekonomisine katkısı bölgesel düzeyde ölçülmektedir. Bu amaçla, Türkiye'de AKE'nin \%5'ten maksimum AKE'ye ulaşması sağlandığında azotlu kimyasal gübre kullanımından sağlanacak ekonomik fayda ilgili yıllar için ortaya konulmaktadır. Çalışmada kullanılan AKE değerleri; 2007-2011 yıllarına ait Türkiye tarımsal üretim verileri kullanılarak oluşturulan, tarımsal alanlarda azot girdi ve çıktı arasındaki ilişkiyi ortaya koyan hiperbolik regresyon modeli ile hesaplanmışır. Yapılan araştırmadan elde edilen sonuçlar neticesinde; AKE'nin iyileştirilmesi ile çiftçiler için önemli ekonomik fayda sağlanacağı, hatta bu faydanın AKE maksimum seviyeye çıkarıldığında toplam azotlu gübre satın alınması için yapılan harcamanın yarısından fazla olacağı tespit edilmiştir. 2007-2011 yılları için azotlu kimyasal gübre satın alınması için yapılan harcamadan sağlanan ekonomik fayda \%5 iyileştirme ve
\end{abstract} maksimum AKE'ye ulaşmada sırasıyla yıllık ortalama 0.49 ve 1.55 milyar TL olmaktadır.

Anahtar Kelimeler: Azot kullanım etkinliği, Azotlu kimyasal gübre, Ekonomik fayda, Tarım ekonomisi

\section{The Evaluation of Contribution of Improving Nitrogen Use Efficiency to Agricultural Economics in Turkey}

\begin{abstract}
Within this study, the contribution of improving nitrogen use efficiency (NUE) in agricultural areas to agricultural economics has been measured regionally for the years of 2007-2011. For this purpose, the economic benefit from use of nitrogenous chemical fertilizers has been presented when improving NUE from $5 \%$ to maximum NUE in Turkey. NUE values used in this study were estimated by using hyperbolic regression model, which states the relationship between nitrogen input and output in agricultural areas. This model was produced by using Turkey agricultural production data for the years of 2007-2011. The results showed that important economic benefit would be gained by improving NUE, even when NUE was improved to maximum level, this benefit would be higher than the half of the expenses for purchasing nitrogenous chemical fertilizers. Yearly average economic benefits gained from purchasing nitrogenous chemical fertilizers would be 0.49 and 1.55 billion TL for the $5 \%$ improving of NUE and reaching maximum NUE, respectively for the years of 2007-2011.
\end{abstract}

Key Words: Nitrogen use efficiency, Nitrogenous chemical fertilizers, Economic benefit, Agricultural economics

\footnotetext{
${ }^{1}$ Bulgular ve değerlendirmeler yazarın kişisel görüşleri olup, hiçbir şekilde Türkiye İstatistik Kurumu’nu bağlamamaktadır.
} 


\section{Giriş}

Bitkiler için önemli bir besin kaynağı olan azotun (N) gerektiğinden az kullanımı bitkisel ürünlerde verimi; fazla kullanımı ise çevre ve insan sağlığını olumsuz yönde etkilemektedir (Sutton et al., 2011a, b; 2013). Bu etkileri; biyoçeşitliliğin olumsuz etkilenmesi, sularda ötrifikasyon ve nitrat birikimi, asidifikasyon, azot oksit emisyonu böylelikle küresel ısınma ve stratosferik ozon tabakasının incelmesi, ozona ve partiküler maddeye maruz kalma riskleri nedeniyle insan sağlığına olumsuz etkiler olarak sıralamak mümkündür (Smil, 2011; Sutton et al., 2011a). Azot kullanımının bu önemine istinaden tarımsal üretimde azot kullanım etkinliğinin (AKE) doğru olarak ölçülmesi kaynak etkin Tarım-Gıda zincirinin sağlanma imkânlarının ortaya konması bakımından oldukça önemlidir (ör. EC, 2011; 2014).

Dünya nüfusunun 2030 yılında 8.5 milyara, 2050 yılında 9.7 milyara (UN, 2016) ulaşacağı tahminleri düşünüldüğünde, artması beklenen nüfusun beslenme ihtiyaçlarını karşılamak için tarımsal alanlarda AKE'nin iyileştirilmesi başka bir ifadeyle daha az kimyasal gübre ile daha fazla bitkisel ürün elde edilmesi önem arz etmektedir. Bununla birlikte kimyasal gübre kullanımının azaltılarak azot kullanım etkinliğinin iyileştirilmesi kimyasal gübrelerin çevre ve insan sağlığına olumsuz etkilerinin azaltılmasına da katkı sağlayacaktır.
Özbek ve Leip (2015) Türkiye'de tarımsal alanlarda AKE'nin bölgeler arasında \%49 ile \%82 arasında değişmekle birlikte ülke genelinde ortalama AKE'nin \%62 olduğunu hesaplamışlardır. Bu durum ülkemizde azotun yaklaşık \%40'ının bitkiler tarafından alınamadığını göstermektedir. $\mathrm{Bu}$ oran bazı bölgelerde \%50'ye kadar çıkmaktadır. Azot kullanım etkinliğinin dünya ortalaması ise $\% 50$ civarındadır (Karaşahin, 2014). Ülkemizin 2015 yılı kimyasal gübre tüketimi 10.8 milyon ton olurken, azotlu gübre tüketimi toplam tüketimin \%66'sına karşılık gelmektedir (TÜiK, 2016a). Azotlu gübre ithalatına yüksek miktarlarda döviz ödenmekte ve üretiminde de çok miktarda fosil yakıt kullanılmaktadır (Karaşahin, 2014). AKE'nin düşük olması bu çerçevede önemli ekonomik kayıplara neden olmaktadır. AKE'nin artırılması üreticiler için üretim maliyetlerinin düşmesini beraberinde getirecektir.

Karaşahin (2014), AKE'yi etkileyen faktörleri ve iyileştirilmesi için yapılması gerekenleri yaptığı literatür taraması ile kapsamlı bir şekilde ortaya koymuştur. Buna göre; AKE'yi iyileştirmek için ürün rotasyonu (münavebe), gübreleme öncesinde toprakta bulunan azot miktarının göz önüne alınması, baklagil bitkilerinin üretim sistemine dahil edilmesi, hibrit veya kültür çeşitlerinin kullanılması, uygun toprak işleme, azot kaynağı olarak amonyumun kullanılması, zamanında ve yapraktan azotun uygulanması ve gelişmiş sulama ve gübreleme yönetim uygulamalarının yapılması uygulanabilecek başlıca 
yaklaşımlardır (Raun et al., 2002; Das et al., 2005; Battilani et al., 2008; Büyük, 2016).

$\mathrm{Bu}$ çalışmanın amacı; AKE'nin belirli oranlarda iyileştirilmesinin tarım ekonomisine dolayısıyla ülke ekonomisine katkısının bölgesel düzeyde ölçülmesidir. Bu amaçla, ülkemizde AKE'nin [\%5-\%AKE-max] oranlarında artırılması sağlandığında azotlu kimyasal gübre kullanımından sağlanacak ekonomik fayda ortaya konulmaktadır.

\section{Materyal ve metot}

Özbek ve Leip (2015) 2007-2011 yıllarına ait Türkiye tarımsal üretim verilerini kullanarak oluşturdukları hiperbolik regresyon modeli ile azot girdi $\left(N_{\text {girdi }}\right)$ ve çıktı $\left(N_{\text {çlktı }}\right)$ arasındaki ilişkiyi ortaya koymuşlar (Eşitlik 1); bu model esas alınarak AKE'yi bölgesel düzeyde hesaplamışlardır (Eşitlik 2). Bu modelde azot girdileri kimyasal gübre, çiftlik gübresi, diğer organik gübreler, atmosferik çökelme, azot fiksasyonu, tohum ve üretim materyalleri kaynaklı azottan oluşurken; azot çıktıları bitkiler ve bitki kalıntıları ile topraktan ayrılan azot ve azot stok değişiminden oluşmaktadır.

$N_{c ̧ l k t l}=\frac{149.5 \cdot N_{\text {girdi }}}{150.5+N_{\text {girdi }}}$

$A K E=\frac{N_{\text {clktt }}}{N_{\text {girdi }}} * 100$

Bu çalışmada, Özbek ve Leip (2015) tarafından hesaplanan Türkiye'de tarımsal alanlarda AKE bilgileri kullanılarak AKE'nin belirli oranlarda iyileştirilmesinin tarım ekonomisine dolayısıyla ülke ekonomisine katkısı bölgesel düzeyde ölçülmektedir. Bu çerçevede, Eşitlik 2 kullanılarak azotlu kimyasal gübre $\left(N_{\text {kimgüb }}\right)$ ile AKE arasındaki ilişki aşağıda belirtildiği gibi ifade edilmiştir (Eşitlik 3). Bu eşitlikte $N_{\text {girdi-dĭger }}, N_{\text {kimgüb }}$ dışındaki diğer azot girdilerini ifade etmektedir.

$N_{k i m g u ̈ b}=\frac{N_{c ̧ l k t t} * 100}{A K E}-N_{g i r d i-d i \breve{g e r}}$

AKE'nin değişimine bağı olarak $N_{\text {kimgüb }}$ 'de meydana gelen değişim aşağıdaki gibi hesaplanmıştır (Eşitlik 4)

$\Delta N_{\text {kimgü } b}=\frac{\Delta A K E * N_{c ̧ l k t \imath} * 100}{A K E_{i l k} * A K E_{\text {Son }}}$

AKE'nin \%5'ten maksimum AKE'ye kadar artırılması sağlandığında azotlu kimyasal gübre kullanımından sağlanacak ekonomik fayda Eşitlik 5'e göre hesaplanmıştır.

Hesaplamalarda maksimum AKE olarak \%85 değeri kullanılmıştır (Özbek and Leip, 2015). Hesaplamalarda kullanılan ortalama $N_{\text {girdi }}, N_{\text {çlktl }}, N_{\text {kimgüb }}$ ve değişimi, AKE ilk ve değişim değerleri Çizelge 1 'de yer almaktadır.

$\boldsymbol{E F}=\Delta \boldsymbol{N}_{\boldsymbol{k i m g} \boldsymbol{u} \boldsymbol{b}} * \boldsymbol{F}_{\boldsymbol{k i m g} \boldsymbol{u} \boldsymbol{b}}$

Bu eşitlikte $E F$, AKE iyileştirildiğinde TL olarak azotlu kimyasal gübre satın alınması için yapılan harcamadan sağlanacak ekonomik faydayı, $\Delta N_{\text {kimgüb }}$ $\mathrm{kgN} \mathrm{ha}^{-1}$ cinsinden azotlu kimyasal gübrede sağlanan azalışı, $F_{\text {kimgüb }}$ azotlu 
Çizelge 1. Ortalama azot girdi, çıktı, kimyasal gübre kullanımı ve değişimi, azot kullanım etkinliği (AKE) ilk ve değişim değerleri, 2007-2011

Table 1. The average values of nitrogen input, output, chemical fertilizer use and change, nitrogen use efficiency initial and change values, 2007-2011

\begin{tabular}{|c|c|c|c|c|c|c|c|c|c|c|c|c|}
\hline \multirow{2}{*}{ Bölgeler } & \multirow{2}{*}{$\begin{array}{c}\mathrm{N}_{\text {girdi }} \\
\left(\mathrm{kgN} \mathrm{ha}^{-1}\right)\end{array}$} & \multirow{2}{*}{$\begin{array}{c}\mathrm{N}_{\text {ç|ktı }} \\
\left(\mathrm{kgN} \mathrm{ha}^{-1}\right)\end{array}$} & \multirow{2}{*}{$\begin{array}{c}N_{\text {kimgüb }} \\
\left(\mathrm{kgN} \mathrm{ha}^{-1}\right)\end{array}$} & \multirow{2}{*}{$\mathrm{AKE}_{\mathrm{ilk}}(\%)$} & \multicolumn{8}{|c|}{$\Delta \mathrm{N}_{\text {kimgüb }}\left(\mathrm{kgN} \mathrm{ha}^{-1}\right)$} \\
\hline & & & & & $\triangle \mathrm{AKE}=5$ & $\triangle \mathrm{AKE}=10$ & $\triangle \mathrm{AKE}=15$ & $\triangle \mathrm{AKE}=20$ & $\triangle \mathrm{AKE}=25$ & $\triangle \mathrm{AKE}=30$ & $\triangle \mathrm{AKE}=35$ & $\Delta \mathrm{AKE}=\mathrm{AK} \mathrm{E}_{\max }-\mathrm{AKE}_{\mathrm{ilk}}$ \\
\hline TR10 & 176 & 81 & 110 & 46 & 17 & 32 & 43 & 53 & 62 & 70 & 76 & 81 \\
\hline TR21 & 132 & 70 & 96 & 53 & 11 & 21 & 29 & 36 & 42 & 48 & 50 & 50 \\
\hline TR22 & 142 & 73 & 55 & 51 & 13 & 23 & 32 & 40 & 47 & 52 & 55 & 55 \\
\hline TR31 & 159 & 77 & 70 & 48 & 15 & 27 & 38 & 46 & 54 & 61 & 67 & 68 \\
\hline TR32 & 104 & 61 & 47 & 59 & 8 & 15 & 21 & 26 & 31 & 32 & 32 & 32 \\
\hline TR33 & 84 & 54 & 34 & 64 & 6 & 11 & 16 & 20 & 21 & 21 & 21 & 21 \\
\hline TR41 & 68 & 47 & 33 & 68 & 5 & 9 & 12 & 13 & 13 & 13 & 13 & 13 \\
\hline TR42 & 167 & 79 & 62 & 47 & 16 & 29 & 40 & 50 & 58 & 62 & 62 & 62 \\
\hline TR51 & 48 & 36 & 25 & 75 & 3 & 6 & 6 & 6 & 6 & 6 & 6 & 6 \\
\hline TR52 & 57 & 41 & 32 & 72 & 4 & 7 & 9 & 9 & 9 & 9 & 9 & 9 \\
\hline TR61 & 99 & 59 & 45 & 60 & 8 & 14 & 20 & 25 & 29 & 29 & 29 & 29 \\
\hline TR62 & 157 & 76 & 112 & 49 & 15 & 27 & 37 & 46 & 53 & 60 & 66 & 67 \\
\hline TR63 & 111 & 63 & 74 & 57 & 9 & 16 & 23 & 29 & 34 & 36 & 36 & 36 \\
\hline TR71 & 49 & 37 & 26 & 75 & 3 & 6 & 6 & 6 & 6 & 6 & 6 & 6 \\
\hline TR72 & 37 & 29 & 13 & 80 & 2 & 2 & 2 & 2 & 2 & 2 & 2 & 2 \\
\hline TR81 & 97 & 59 & 24 & 60 & 7 & 14 & 19 & 24 & 24 & 24 & 24 & 24 \\
\hline TR82 & 65 & 45 & 19 & 69 & 4 & 8 & 12 & 12 & 12 & 12 & 12 & 12 \\
\hline TR83 & 81 & 52 & 38 & 65 & 6 & 11 & 15 & 20 & 20 & 20 & 20 & 20 \\
\hline TR90 & 63 & 44 & 33 & 70 & 4 & 8 & 11 & 11 & 11 & 11 & 11 & 11 \\
\hline TRA1 & 33 & 27 & 4 & 81 & 1 & 1 & 1 & 1 & 1 & 1 & 1 & 1 \\
\hline TRA2 & 62 & 44 & 5 & 70 & 4 & 5 & 5 & 5 & 5 & 5 & 5 & 5 \\
\hline $\begin{array}{l}\text { TRB1 } \\
\end{array}$ & 39 & 31 & 9 & 79 & 2 & 3 & 3 & 3 & 3 & 3 & 3 & 3 \\
\hline TRB2 & 71 & 48 & 4 & 68 & 4 & 4 & 4 & 4 & 4 & 4 & 4 & 4 \\
\hline TRC1 & 73 & 49 & 39 & 67 & 5 & 9 & 13 & 15 & 15 & 15 & 15 & 15 \\
\hline TRC2 & 93 & 57 & 57 & 61 & 7 & 13 & 18 & 23 & 26 & 26 & 26 & 26 \\
\hline TRC3 & 95 & 58 & 41 & 61 & 7 & 13 & 19 & 24 & 27 & 27 & 27 & 27 \\
\hline
\end{tabular}

Not: AKE \%85'i geçemediğinden (bkz. Materyal ve Metot), hesaplamalarda $A K E_{\text {son }}\left(=A K E_{i k}+\Delta A K E\right)$ değerleri $\% 85^{\prime} i$ aşan bölgeler için $A K E_{\max }=\% 85$ değerleri kullanılmıştır. Bu durumda $\triangle A K E=A K E_{\max }-A K E_{i k}$ olarak

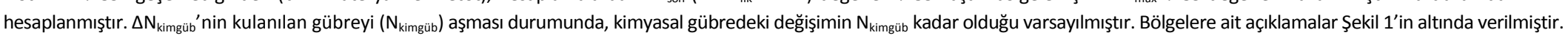


Çizelge 2. Azotlu gübre kullanım miktarları ve çiftçi alış fiyatları, 2007-2011

Table 2. The amount of nitrogenous fertilizer and farmer purchase price, 2007-2011

\begin{tabular}{|c|c|c|c|c|c|c|c|c|c|c|c|c|c|c|c|}
\hline \multirow[t]{2}{*}{ TL ton ${ }^{-1}$} & \multicolumn{3}{|c|}{2007} & \multicolumn{3}{|c|}{2008} & \multicolumn{3}{|c|}{2009} & \multicolumn{3}{|c|}{2010} & \multicolumn{3}{|c|}{2011} \\
\hline & a & $b$ & c & a & $b$ & c & a & $b$ & c & a & $b$ & c & a & b & c \\
\hline Amonyum sülfat & & & & & & & & & & & & & & & \\
\hline $\begin{array}{l}\text { Ammonium sulphate } \\
(\% 21 \mathrm{~N})\end{array}$ & 359927 & 354 & 1684 & 292460 & 606 & 2887 & 460787 & 349 & 1664 & 456613 & 373 & 1776 & 413110 & 572 & 2723 \\
\hline Amonyum nitrat & & & & & & & & & & & & & & & \\
\hline $\begin{array}{l}\text { Ammonium nitrate } \\
(\% 26 \mathrm{~N})\end{array}$ & 1005838 & 376 & 1447 & 809726 & 548 & 2109 & 953613 & 469 & 1803 & 736375 & 472 & 1815 & 733193 & 603 & 2320 \\
\hline Amonyum nitrat & & & & & & & & & & & & & & & \\
\hline $\begin{array}{l}\text { Ammonium nitrate } \\
(\% 33 \mathrm{~N})\end{array}$ & 889969 & 441 & 1336 & 744245 & 629 & 1907 & 1014338 & 515 & 1560 & 872652 & 571 & 1730 & 842090 & 729 & 2209 \\
\hline Ü r e - Urea (\%46 N) & 772232 & 647 & 1407 & 770231 & 817 & 1776 & 808253 & 677 & 1472 & 879523 & 678 & 1475 & 760295 & 960 & 2087 \\
\hline Diamonyum fosfat & & & & & & & & & & & & & & & \\
\hline $\begin{array}{l}\text { Diammonium phosp. } \\
(\% 18 \mathrm{~N})\end{array}$ & 428012 & 779 & 4330 & 149098 & 1797 & 9986 & 665435 & 741 & 4115 & 495465 & 988 & 5488 & 386467 & 1464 & 8134 \\
\hline 20.20 .0 & 718200 & 530 & 2650 & 542192 & 1193 & 5966 & 703818 & 559 & 2795 & 701586 & 663 & 3316 & 679739 & 1036 & 5182 \\
\hline $\begin{array}{l}\text { Diğer } \\
\text { Other }\end{array}$ & 895761 & 521 & 2142 & 769986 & 932 & 4105 & 629643 & 552 & 2235 & 782858 & 624 & 2600 & 895460 & 894 & 3776 \\
\hline
\end{tabular}

Kaynak: BÜGEM, 2016

a: Gübre tüketim miktarı (ton), b: Gübre birim fiyatı $\left(\operatorname{TL~ton~}^{-1}\right)$, c: Azot birim fiyatı (TL (ton N) ${ }^{-1}$ )

a: Fertilizer use amount (ton), b: Fertilizer unit price $\left(T L \operatorname{ton}^{-1}\right)$, c: Nitrogen unit price (TL (ton $\left.N\right)^{-1}$ )

Not: Gübre türlerine ait çiftçi alış fiyatları 12 aylık ortalama üretici, ithalatçı firma fiyatlarına \%7.5 artış uygulanarak hesaplanmıştır (BÜGEM, 2016). Diğer azotlu gübrelerin fiyatları için azotlu gübrelerin ortalama fiyatları kullanıımıştır. 
kimyasal gübrenin $\mathrm{TL} \mathrm{kgN}^{-1} \mathrm{ha}^{-1}$ cinsinden yıllık ortalama birim fiyatını ifade etmektedir. $F_{\text {kimgüb }}$, gübre türlerine ait fiyatların azot tüketim miktarlarına göre ağırlıklı ortalaması kullanılarak hesaplanmıştır.

2007-2011 yıllarında Türkiye'deki azotlu gübre tüketiminin \%83'ünü oluşturan amonyum sülfat (\%21 N), amonyum nitrat (\%26 ve \%33 N), üre (\%46 $\mathrm{N}$ ), diamonyum fosfat (\%18 N) ve 20.20.0 $(\% 20 \mathrm{~N})$ gübre türlerine ait çiftçi alış fiyatları 12 aylık ortalama üretici, ithalatçı firma fiyatlarına \%7.5 artış uygulanarak hesaplanmıştır (BÜGEM, 2016). Diğer azotlu gübrelerin fiyatları için bu gübrelerin ortalama fiyatları kullanılmıştır (Çizelge 2).

Bölgesel analizlerde Türkiye İstatistik Kurumu (TÜiK) tarafından oluşturulan İstatistikî Bölge Birimleri Sınıflaması Düzey 2 bilgileri kullanılmıştır (Şekil 1).

\section{Araştırma Bulguları ve Tartışma}

2007-2011 yılları arasında azotlu kimyasal gübre satın alınması için yapılan yıllık ortalama harcama 3 milyar TL'dir. Ülkemizde azotlu kimyasal gübre satın alınması için yapılan harcamanın bölgelere göre dağılımı incelendiğinde en fazla harcama yapılan bölgenin toplam içinde \%10'luk payla TRC2 olduğu görülmektedir. Bu bölgeyi \%9 ve $\% 8^{\prime}$ lik paylarla TR62 ve TR21 izlemektedir (Şekil 1). En az harcama yapılan bölge ise $\% 1^{\prime}$ lik payla TRA1'dir.

Bölgelere göre azotlu kimyasal gübre harcamaları bölgedeki tarımsal alan büyüklüğü ve yetiştirilen bitkisel ürün türü ve topraktaki organik madde miktarına bağlı olarak dekara gübre tüketimine göre değişmektedir. AKE'nin iyileştirilmesine yönelik önlemlerin alınması aynı miktarda bitkisel üretim için dekara azotlu gübre tüketimini azaltacak buna bağlı olarak da gübre harcamalarında azalmaya neden olacaktır. Türkiye'de bölgeler arasında AKE'ler \%49 ile \%82 arasında değişmekte olup bölgeler arasında önemli farklılıklar söz konusudur (Özbek and Leip, 2015). Tüm bölgelerde AKE Türkiye için maksimum AKE düzeyi olarak kabul edilen \%85'in (Özbek and Leip, 2015) altındadır. $\mathrm{Bu}$ durum; AKE'nin iyileştirilmesi ile tüm bölgelerde azotlu gübre tüketiminin azaltılmasına bağlı olarak ekonomik fayda sağlanacağını göstermektedir.

Kartalkanat (2016) 2010 yılında Türkiye'de kimyasal gübre için ödenen toplam bedelin 3.8 Milyar TL olduğunu belirtmektedir. Azotlu kimyasal gübre tüketiminin 2007-2011 yılları arasında toplam içindeki payının ortalama \%67 (BÜGEM, 2016) olduğu düşünüldüğünde bu çalışma ile hesaplanan 2007-2011 yılları arasında azotlu kimyasal gübre satın alınması için yapılan yılık ortalama harcama değerinin (3 milyar TL) bu bilgi ile tutarlı olduğu görülmektedir.

AKE'nin \%5 iyileştirilmesi ile 20072011 yılları arasında azotlu kimyasal gübre satın alınması için yapılan yıllık ortalama harcamadan 0.49 milyar TL; maksimum AKE'ye ulaşıldığında ise $\mathbf{1 . 5 5}$ milyar TL ekonomik fayda sağlamak mümkün olmaktadır (Şekil 2). 


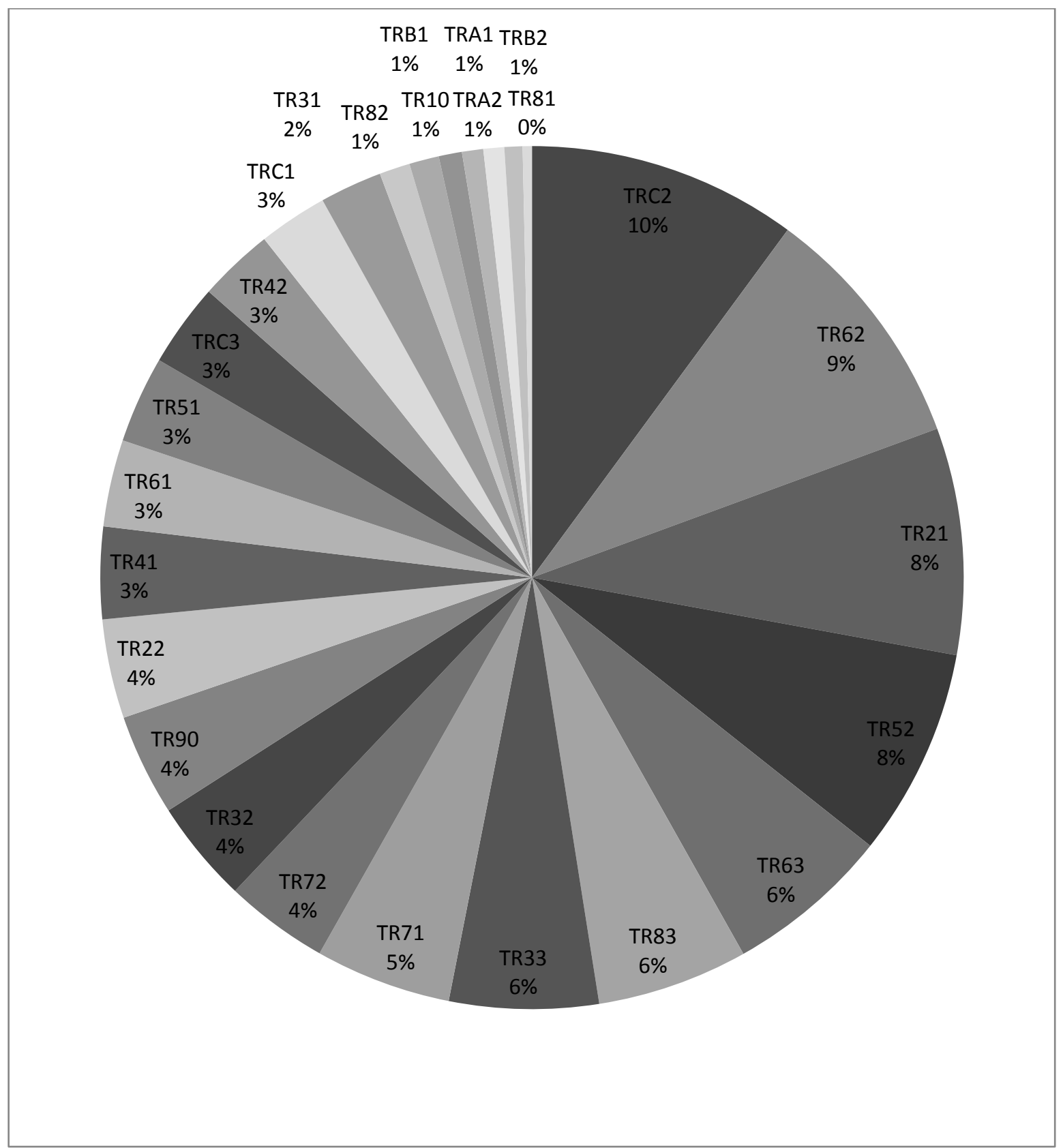

Şekil 1. Azotlu kimyasal gübre satın alınması için yapılan yıllık ortalama harcamanın bölgelere göre dağılımı, 2007-2011

Figure 1. Yearly average expense for purchasing of nitrogenous fertilizer by regions, 2007-2011 TR10: İstanbul, TR21: Tekirdağ, Edirne, Kırklareli, TR22: Balıkesir, Çanakkale, TR31: İzmir, TR32: Aydın, Denizli, Muğla, TR33: Manisa, Afyon, Kütahya, Uşak, TR41: Bursa, Eskişehir, Bilecik, TR42: Kocaeli, Sakarya, Düzce, Bolu, Yalova, TR51: Ankara, TR52: Konya, Karaman, TR61: Antalya, Isparta, Burdur, TR62: Adana, Mersin, TR63: Hatay, Kahramanmaraş, Osmaniye, TR71: Kırıkkale, Aksaray, Niğde, Nevşehir, Kırşehir, TR72: Kayseri, Sivas, Yozgat, TR81: Zonguldak, TR82: Kastamonu, Çankırı, Sinop, TR83: Samsun, Tokat, Çorum, Amasya, TR90: Trabzon, Ordu, Giresun, Rize, Artvin, Gümüşhane, TRA1: Erzurum, Erzincan, Bayburt, TRA2: Ağrı, Kars, Iğdır, Ardahan, TRB1: Malatya, Elazı̆̆, Bingöl, Tunceli, TRB2: Van, Muş, Bitlis, Hakkari, TRC1: Gaziantep, Adıyaman, Kilis, TRC2: Şanlıurfa, Diyarbakır, TRC3: Mardin, Batman, Şırnak, Siirt 


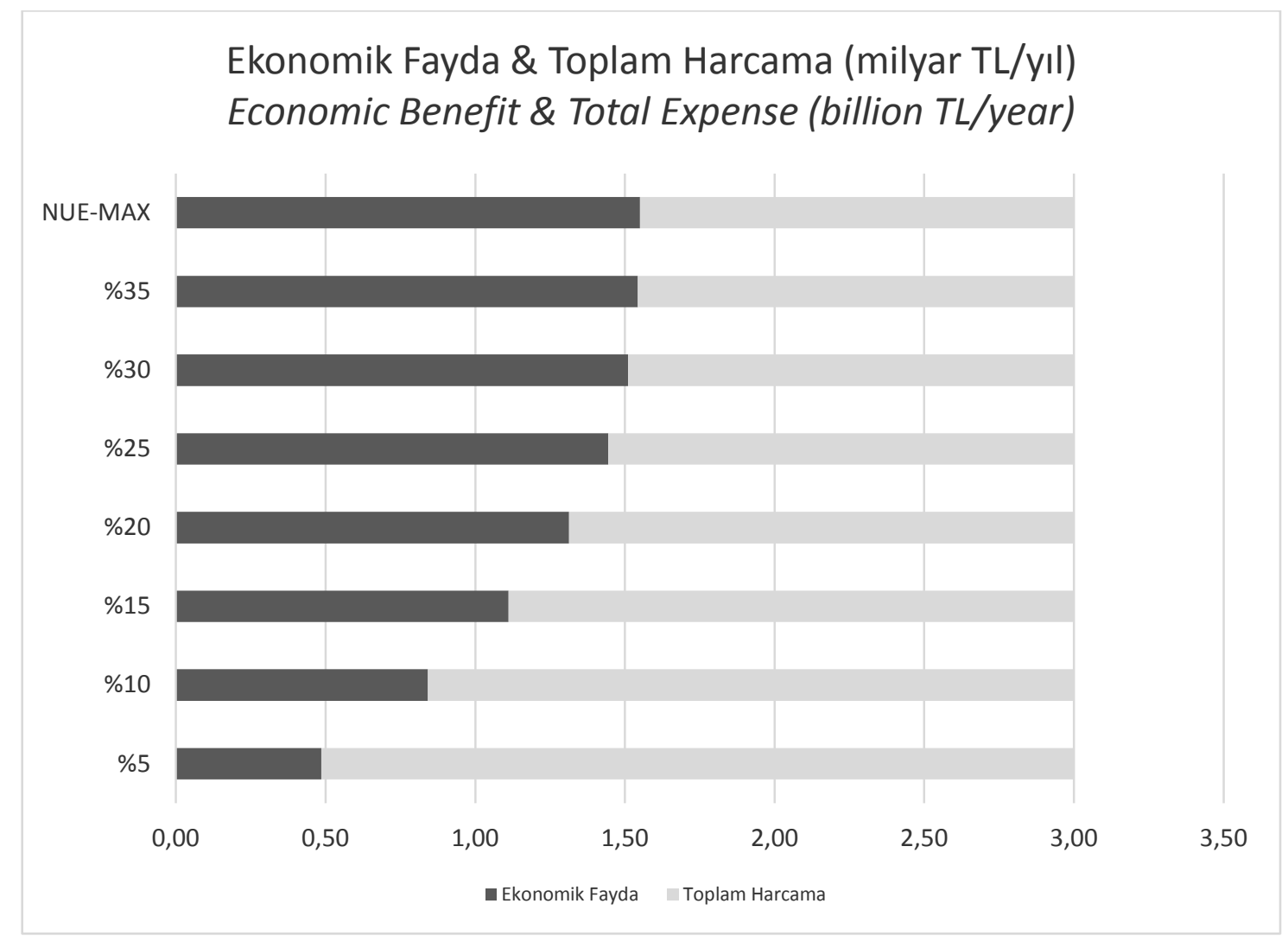

Şekil 2. Azotlu kimyasal gübre satın alınması için yapılan harcamadan sağlanan yıllık ortalama ekonomik fayda, 2007-2011

Figure 2. Yearly average economic benefit gained from expense for purchasing of nitrogenous fertilizer, 2007-2011

AKE'nin iyileştirilmesi çiftçiler için önemli ekonomik fayda sağlamaktadır; hatta bu fayda AKE maksimum seviyeye çıkarıldığında toplam azotlu gübre satın alınması için yapılan harcamanın yarısından fazla olmaktadır (Şekil 2). Bu durum; çitçiler için önemli maliyet kalemlerinden olan gübre kullanımının AKE'nin iyileştirilmesine yönelik alınacak önlemlerle önemli miktarda azaltılabileceğini göstermektedir. Bu önlemler arasında çiftçilere AKE'nin iyileştirilmesine yönelik eğitim ve yayım hizmetlerinin verilmesi önemli bir yere sahiptir.
AKE maksimum seviyeye çıkartıldığında azotlu kimyasal gübre satın alınması için yapılan harcamadan sağlanan ekonomik faydanın bölgelere göre dağılımı incelendiğinde en büyük ekonomik faydanın yıllık ortalama 168 milyon TL ile TR62 bölgesinde gerçekleştiği görülmektedir. Bu bölgeyi 136 milyon TL ile TRC2 bölgesi, 132 milyon TL ile TR21 bölgesi izlemektedir. AKE maksimum seviyeye çıkartıldığında en küçük ekonomik faydanın 9 milyon TL ile TRA1 bölgesinde gerçekleştiği görülmektedir. Bu bölgeyi 10 milyon TL ile TR81 bölgesi, 11 milyon TL ile TRB1 bölgesi izlemektedir (Şekil 3). 


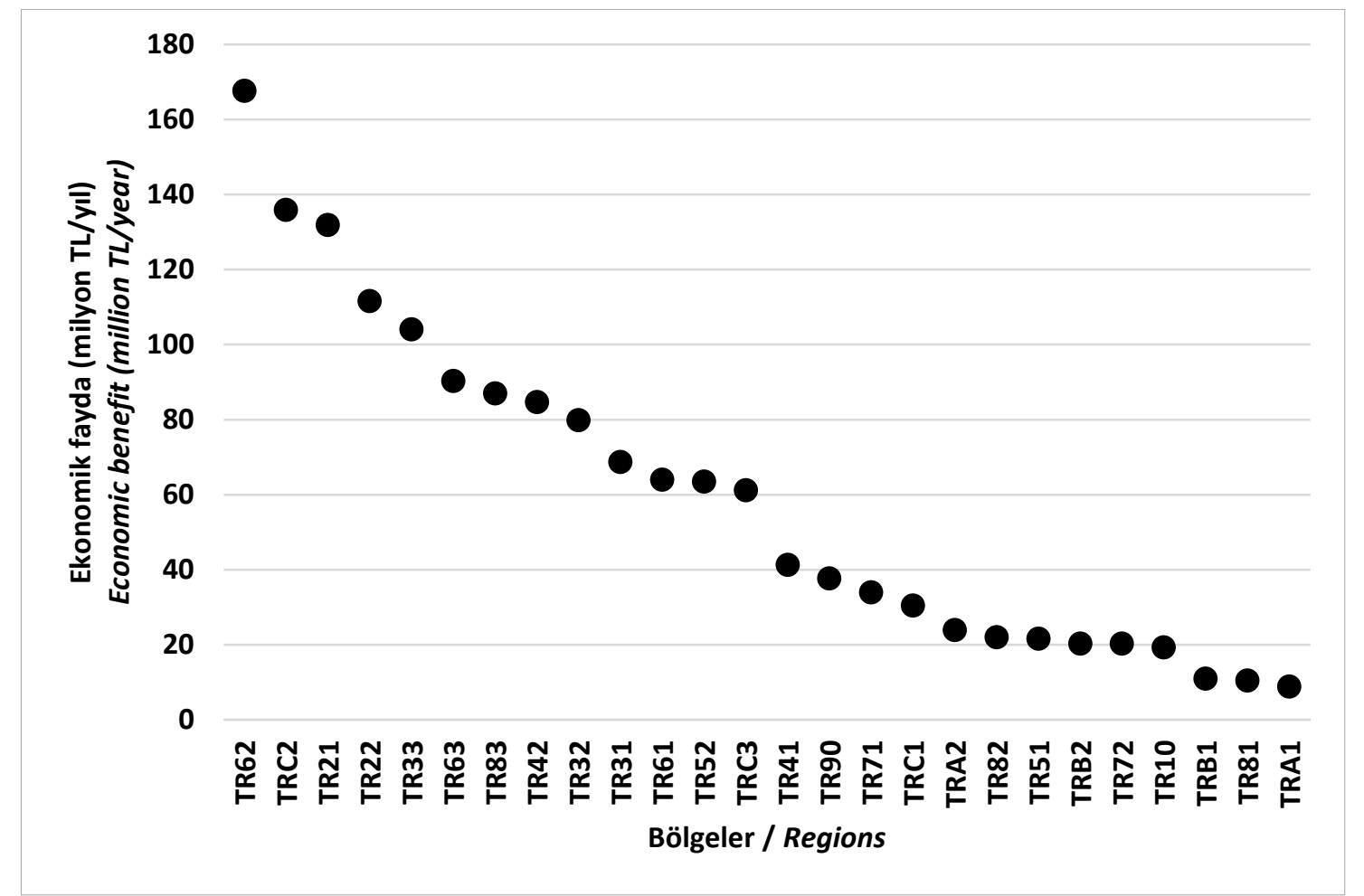

Şekil 3. AKE maksimum seviyeye çıkartıldığında azotlu kimyasal gübre satın alınması için yapılan harcamadan sağlanan yıllık ortalama ekonomik faydanın bölgelere göre dağılımı, 2007-2011

Figure 3. Yearly average economic benefit gained from expense for purchasing of nitrogenous fertilizer by regions when NUE is maximum, 2007-2011

AKE maksimum seviyeye ihracatın (ihracat-ithalat) artması ile gayri çıkartıldığında Türkiye genelinde 2007- safi yurtiçi hâsılada (GSYiH) artışı da 2011 yılları için istihdam edilen kişi başına düşen yıllık ortalama kâr artışı 288 $\mathrm{TL} /$ kişi/yı olmaktadır. Bu artışın bölgelere göre dağılımı incelendiğinde en yüksek artış 1285 TL ile TR10 bölgesinde; en düşük artış ise 52 TL ile TRA1 bölgesinde gerçekleşmektedir (Şekil 4).

Kimyasal gübre kullanımında dışa bağımlılı̆ın fazla olması (DPT, 2000) nedeniyle AKE'nin iyileştirilmesi ile kimyasal gübre talebindeki azalış ithalattaki azalışı da beraberinde getirecektir. Bunun yanı sıra, üretim düzeyini korumak isteyen kimyasal gübre üretimi yapan firmalar iç piyasalardan dış piyasalara yönelerek ihracat artışına neden olacaklardır. $\mathrm{Bu}$ durum net beraberinde getirecektir.

Kimyasal gübre kullanımı azaldığında gübre için kullanılan işgücü ve çekigücü masraflarında değişiklik meydana gelebilecektir. İşgücü ve çekigücü masrafları; bazı ürünlerde gübrelemenin diğer işlemlerle beraber yapılması (ör. ekimle birlikte gübreleme), elle ya da makine kullanılarak yapılması, makinenin üreticinin mülkü olup olmaması, gübreleme işleminin hanehalkı ya da yevmiyeli iş̧iler tarafından yapılıp yapılmaması durumlarına bağlı olarak değişkenlik göstermektedir. Bu değişkenlikten dolayı işgücü ve çekigücü masraflarındaki değişimi tam olarak hesaplamak mümkün olmamaktadır. 


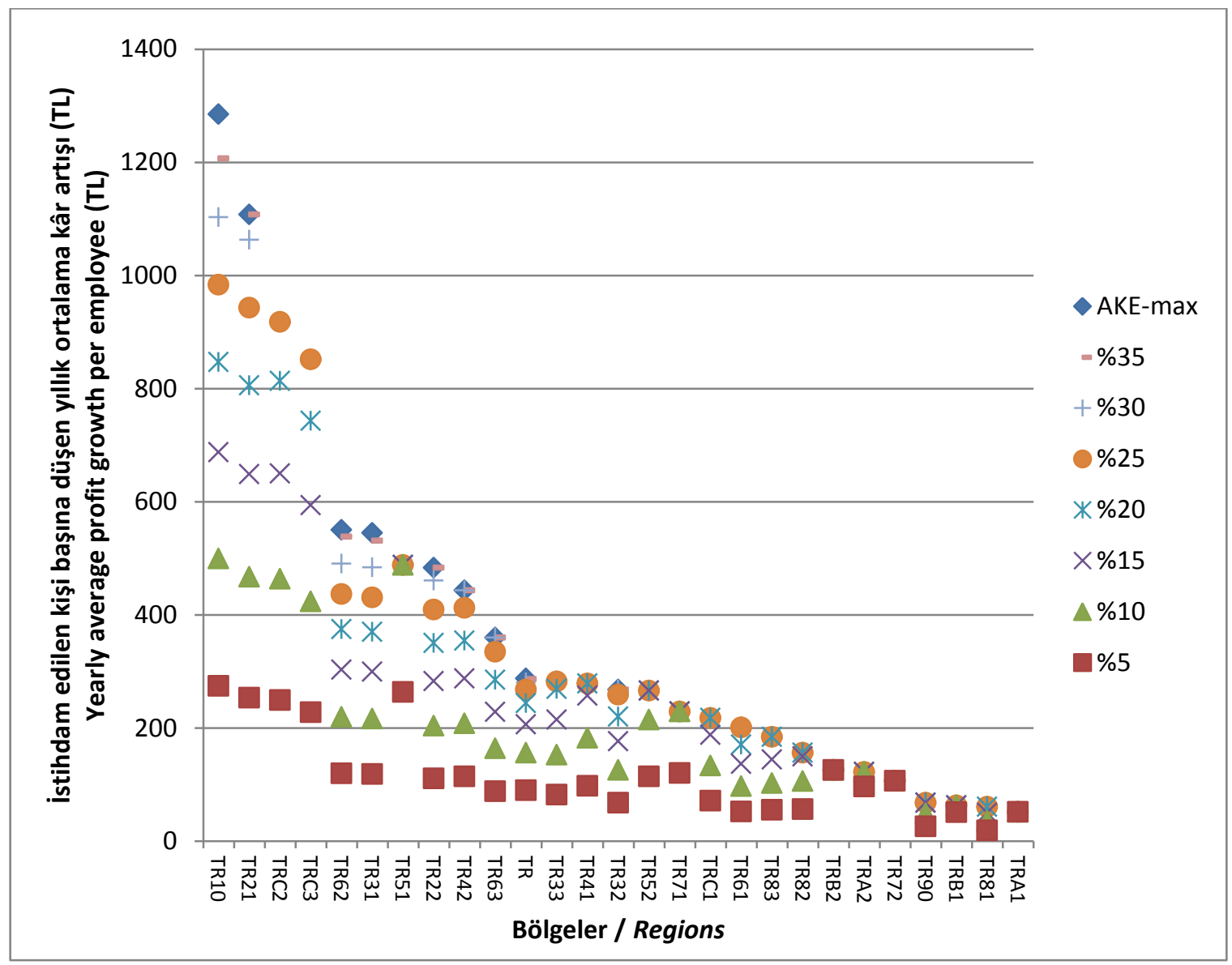

Şekil 4. AKE maksimum seviyeye çıkartıldığında istihdam edilen kişi başına düşen yıllık ortalama kâr artışının bölgelere göre dağılımı, 2007-2011

Figure 4. Yearly average profit growth per employee by regions when NUE is maximum, 2007-2011

\section{Sonuçlar}

Yapılan araştırmadan elde edilen sonuçlar neticesinde; AKE'nin iyileştirilmesi ile çiftçiler için önemli ekonomik fayda sağlanacağı, hatta bu faydanın AKE maksimum seviyeye çıkarıldığında toplam azotlu gübre satın alınması için yapılan harcamanın yarısından fazla olacağı ortaya konmuştur. 2007-2011 yılları için azotlu kimyasal gübre satın alınması için yapılan harcamadan sağlanan ekonomik fayda $\% 5$ iyileştirme ve maksimum AKE'ye ulaşmada sırasıyla yıllık ortalama 0.49 ve
1.55 milyar TL olmaktadır. Bu fayda üreticiler için üretim maliyetlerinin düşmesini dolayısıyla karlılığın artmasını beraberinde getirecektir.

Bunun yanı sıra AKE'nin iyileştirilmesi için gerekli tedbirlerin alınması kimyasal gübre kullanımını azaltarak azotun fazla kullanımından kaynaklı biyoçeşitliliğin olumsuz etkilenmesi, sularda ötrifikasyon ve nitrat birikimi, asidifikasyon, azot oksit emisyonu böylelikle küresel ısınma ve stratosferik ozon tabakasının incelmesi, ozona ve partiküler maddeye maruz kalma riskleri nedeniyle insan sağlığına olumsuz etkiler gibi çevre ve insan sağlığını olumsuz yönde etkileyen 
faktörlerin ortadan kalkmasına katkı sağlayacaktır. Bu yönüyle AKE'nin iyileştirilmesi ekonomik yönden uygulanabilir, çevre açısından uygun, sosyal yönden kabul edilebilir ve politik yönden desteklenebilir tarım şekli olarak tanımlanan sürdürülebilir tarım uygulamaları için oldukça önem arz etmektedir.

Ülkemizde toplumun eğitim seviyesi en düşük kesimini oluşturan tarım sektöründe eğitim ve yayım hizmetleri yeterli düzeyde değildir (Eraslan ve diğ. 2010). Yapılan çalışmalar çiftçilerin; gübre miktarını, çeşidini ve gübreleme zamanını büyük oranda kendi bilgi ve tecrübelerine göre belirlediklerini ortaya koymaktadır (ör. Yılmaz ve diğ., 2009; Acar ve Gül, 2015). Yılmaz ve diğ. (2009) tarafından yapılan çalışmada çiftçilerin \%79'unun gübre ve gübreleme ile ilgili herhangi bir çiftçi eğitim faaliyetine katılmadıkları belirlenmiştir. Çiftçilere AKE'nin iyileştirilmesine yönelik eğitim ve yayım hizmetlerinin düzenli ve kararlı bir şekilde verilmesi; çiftçilerin kendi bilgi ve tecrübelerine dayalı uygulamalardan etkin gübreleme yönetim sistemlerine geçmelerine katkı sağlayacaktır. Böylelikle; çiftçi uygulamaları ve gübre yönetimine bağlı olan halihazırda düşük seviyelerde olan AKE'nin iyileştirilmesi sağlanacaktır.

AKE'nin iyileştirilmesi ile sağlanacak ekonomik, çevresel ve insan sağlığı kazanımlarının önemine istinaden AKE'yi iyileştirmek için ürün rotasyonu, gübreleme öncesinde toprakta bulunan azot miktarının göz önüne alınması, baklagil bitkilerinin üretim sistemine dâhil edilmesi, hibrit veya kültür çeşitlerinin kullanılması, uygun toprak işleme, azot kaynağı olarak amonyumun kullanılması, zamanında ve yapraktan azotun uygulanması ve gelişmiş sulama ve gübreleme yönetim uygulamalarının yapılması gibi yaklaşımların hayata geçirilmesi için eğitim ve yayım hizmetleri başta olmak üzere gerekli tedbirlerin alınması ve tarımsal politikaların bu yönde oluşturulması önerilmektedir.

\section{Kaynaklar}

Acar, M., Gül, M., 2015. Havuç Yetiştiriciliğinin Teknik Yapısı ve Değişimi: Konya İi Örneği, Journal of Agricultural Faculty of Mustafa Kemal University, 20(1):43-53.

Battilani, A., Plauborg, F.L., Hansen, S. , Dolezal, F., Mazurczyk, W., Bizik, Z., 2008. Nitrogen uptake and nitrogen use efficiency of fertigated potatoes. $V^{\text {th }}$ IS on Irrigation of Hort. Crops, 61-67.

BÜGEM., 2016. BÜGEM faaliyetleri, http://www.tarim.gov.tr/sgb/Belgeler/Sag MenuVeriler/BUGEM.pdf. Erişim: Ekim, 2016.

Büyük, G., 2006. Çukurova Koşullarında Mısır Çeşitlerinde Değişik Dönemlerde Uygulanan Farklı Azot Dozlarının Azot Kullanım Etkinliğine, Tane Verimine ve Kaliteye Etkisi" Doktora Tezi. Çukurova Üniversitesi Fen Bilimleri Enstitüsü Toprak Ana Bilim Dalı. 143 sayfa, Adana.

Das, A., Munda, G.C., Patel, D.P., 2005. Technological options for improving nutrient and water use efficiency. http://www.kiran.nic.in/pdf/publications/ Water_Use_Efficiency.pdf. Erişim: Ekim, 2016.

DPT., 2000. Gübre sanayii özel ihtisas komisyonu raporu.

http://www.kalkinma.gov.tr/Lists/zel\%20h tisas\%20Komisyonu\%20Raporlar/Attachm ents/87/oik531.pdf. Erişim: Ekim, 2016.

EC., 2011. Communication from the Commission to the European Parliament, the Council, the European Economic and Social 
Committee and the Committee of the Regions. Roadmap to a Resource Efficient Europe. COM(2011) 571 final. http://eurlex.europa.eu/legalcontent/EN/AUTO/?uri=COM:2011:0571:F IN. Erişim: Mart, 2015.

EC., 2014. Communication from the Commission to the European Parliament, the Council, the European Economic and Social Committee and the Committee of the Regions. Towards a circula economy: A zero waste programme for Europe. $\operatorname{COM}(2014) 398$ final. http://eurlex.europa.eu/legalcontent/EN/TXT/HTML/?uri=CELEX:52014 DC0398\&from=EN. Erişim: Mart, 2015.

Eraslan, F., İnal, A., Güneş, A., Erdal, İ., Coşkan, A., 2010. Türkiye'de kimyasal gübre üretim ve tüketim durumu, sorunlar, çözüm önerileri ve yenilikler. TMMOB Ziraat Mühendisleri Odası, Ziraat Mühendisliği VII. Teknik Kongresi. 11-15 Ocak 2010, Ankara.

Karaşahin, M., 2014. Bitkisel Üretimde Azot Alım Etkinliği ve Reaktif Azotun Çevre Üzerine Olumsuz Etkileri, APJES II-III (2014) 15-21, Doi: 10.5505/apjes.2014.38247.

Kartalkanat, A., 2016. Gübre Satışlarına İlişkin Çıkmazlar.

http://arsiv.gidatarim.com/Yazarlarimiz/2 5585_156_AHMET-KARTALKANAT-GubreSatislarina-Iliskin-Cikmazlar.html. Erişim: Ekim, 2016.

Özbek, F.Ş., Leip, A., 2015. Estimating the gross nitrogen budget under soil nitrogen stock changes: a case study for Turkey. Agriculture, Ecosystems \& Environment 2(1): 109.

Smil, V., 2011. Nitrogen cycle and world food production. World Agriculture 2, 9-13.

Sutton, M.A., C.M. Howard, J.W. Erisman, G. Billen, A. Bleeker, P. Grennfelt, H. van Grinsven, B. Grizzetti., 2011a. The European Nitrogen Assessment: Sources, effects and policy perspectives.
Cambridge, Cambridge University Press. ISBN: 978110700612.

Sutton, M.A., Oenema, O., Erisman, J.W., Leip, A., van Grinsven, H., Winiwarter, W., 2011b. Too much of a good thing. Nature 472, 159-61. doi:10.1038/472159a.

Sutton, M.A., A. Bleeker, C.M. Howard, M. Bekunda, B. Grizzetti, W. de Vries, H.J.M. Van Grinsven, Y.P. Abrol, T.K. Adhya, G. Billen, E. Davidson, A. Datta, R. Diaz, J.W. Erisman, X.J. Liu, O. Oenema, C. Palm, N. Raghuram, S. Reis, R.W. Scholz, T. Sims, H. Westhoek, F.S. Zhang., 2013. Our Nutrient World: The challenge to produce more food and energy with less pollution. Centre for Ecology and Hydrology, Edinburgh on behalf of the Global Partnership on Nutrient Management and the International Nitrogen Initiative. http://www.initrogen.org/sites/default/fi les/documents/files/ONW.pdf. Erişim: Mart, 2015.

Raun, W.R., J.B. Solie, G.V. Johnson, M.L. Stone, R.W. Mullen, K.W. Freeman, W.E. Thomason, E.V. Lukina., 2002. Improving nitrogen use efficiency in cereal grain production with optical sensing and variable rate application. Agron. J., 94: 815-820.

TÜik., 2016a. Bitkisel üretim istatistikleri. http://www.tuik.gov.tr/PreTablo.do?alt_id =1001. Erişim: Ekim, 2016.

UN., 2016. World Population Prospects: The 2015 Revision. Population Division of the Department of Economic and Social Affairs of the United Nations Secretariat, https://esa.un.org/unpd/wpp/. Erişim: Ekim, 2016.

Yılmaz, H., Demircan, V., Gül, M., 2009. Üreticilerin kimyasal gübre kullanımında bilgi kaynaklarının belirlenmesi ve tarımsal yayım açısından değerlendirilmesi. Süleyman Demirel Üniversitesi Ziraat Fakültesi Dergisi, 4 (1): 31-44. 